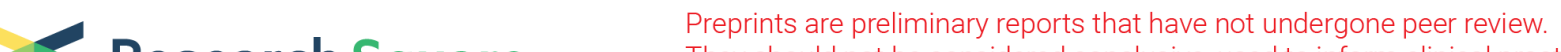 Research Square They should not be considered conclusive, used to inform clinical practice, or referenced by the media as validated information.
}

\section{Implementation of the POGIL-based flipped classroom learning: an approach to promote learning in emergency medicine}

yishu tang

Central South University Third Xiangya Hospital

huaizheng liu

Central South University Third Xiangya Hospital

Kefu Zhou

Central South University Third Xiangya Hospital

tianyi zhang

Central South University Third Xiangya Hospital

Chuanzheng Sun ( $\nabla$ 26774204@qq.com )

Central South University Third Xiangya Hospital

Research article

Keywords: process-oriented guided-inquiry learning, flipped classroom, teaching model, emergency medicine, teaching quality

Posted Date: June 9th, 2020

DOI: https://doi.org/10.21203/rs.3.rs-29069/v1

License: (c) (i) This work is licensed under a Creative Commons Attribution 4.0 International License. Read Full License 


\section{Abstract}

Background: As the Emergency medicine is a multidisciplinary discipline, the emergency medicine education is focuses on teaching students to think actively. The flipped classroom was widely used in various medicine teaching that can improve the efficacy of classroom learning. While the processoriented guided-inquiry learning (POGIL), which be proved can promoting active learning and critical thinking.We assume that both two teaching methods may complement each other in emergency medicine education.

Object: To evaluate the student' learning effectiveness and acceptability of the process-oriented guidedinquiry learning (POGIL)-based flipped classroom model for teaching emergency medicine education.

Methods: A total of 90 students majoring in clinical medicine at Xiangya School of Medicine, Central South University, were enrolled in this study. They were randomly divided into an experimental group and control group, with 45 students in each group. The experimental group adopted the POGIL-based flipped classroom model, and the control group adopted the traditional teaching model; teaching effectiveness was evaluated through tests, an operation exam and questionnaire surveys.

Results: After the completion of the course, the scores of the two groups were compared. The theoretical and operational scores of the experimental group were higher than those of the control group, and the differences were statistically significant $(P<0.05)$. The learning interest, clinical thinking ability, and acceptance of the teaching model for the students in the experimental group were significantly higher than those for students in the control group, and the differences were statistically significant $(P<0.05)$.

Conclusion: The POGIL-based flipped classroom model can significantly improve students' scores, students' acceptance of the teaching model, and teaching quality.

\section{Background}

Emergency medicine is a new interdisciplinary field in clinical medicine and covers 22 medical specialties, including internal medicine, surgery, obstetrics and gynecology, pediatrics and infectious diseases. Its teaching focus is to train students to evaluate and deal with various complicated and changeable conditions of emergency patients in a short time, and students are required to master comprehensive clinical knowledge and have active divergent thinking; therefore, learning and teaching this course are more difficult than they are for other medical courses [1].

In China, the traditional teaching model for emergency medicine uses PPT and adopts the "cramming" method. Teachers are unable to reflect the "urgency" and "complexity" of emergency medicine through limited teaching time. Students passively receive knowledge, have insufficient independent thinking and have limited learning enthusiasm [2]. In clinical practice, when facing patients with the same clinical manifestations but different causes, it is impossible for students to apply knowledge learned from books to real cases. Therefore, teaching emergency medicine has always been a difficult and weak point in 
clinical medical education. Despite the use of problem-based learning (PBL), computer-based learning $(\mathrm{CBL})$ and even team-based learning (TBL) to assist in various teaching models, the differences in students' learning ability and knowledge background cause inconsistent teaching effects [3-5]. Improving the critical thinking ability of students and increasing students' interest in learning emergency medicine have become urgent issues in the reform of the current emergency medicine teaching model.

Process-oriented guided-inquiry learning (POGIL) is a new student-oriented teaching method. In this teaching model, situational teaching is integrated into the classroom to guide students to explore and learn, in order to train students to think creatively and to use knowledge purposefully [6]. In recent years, the flipped classroom method has been shown to effectively stimulate students' interest in learning and improve students' independent thinking, practical skills and ability to collaborate. Therefore, to improve teaching effectiveness, we, for the first time, applied an innovative POGIL-based flipped classroom model for teaching emergency medicine and analyzed and compared the teaching effects between this new teaching model and the traditional teaching method, in order to explore a new model for teaching emergency medicine.

\section{Methods}

\section{Participants}

A total of 90 fourth-year medical students majoring in clinical medicine at the Xiangya School of Medicine Central South University were enrolled.Among them, 40 were eighth-year medical students, and 50 were fifth-year medical students (2015 class); 38 were male, and 52 were female. They were randomly divided into an experimental group and a control group, with 45 students in each group. General information regarding the students in two groups was comparable, and differences were not statistically significant $(P>0.05)$, as shown in Table 1.

\section{Study design}

Teaching methods The emergency medicine program content includes cardio-pulmonary resuscitation (CPR) and electric defibrillation and treatments for trauma, acute chest pain, acute abdominal pain, poisoning and other common critical illnesses. The teachers in the two groups were the same and were senior attending or associate professors with extensive clinical experience. The traditional teaching model was used in the control group. For the experimental group, the POGIL-based flipped classroom model was adopted, in which the teachers prepared videos related to the teaching content and sent them to the students before class so that the students could watch the videos, be familiar with the cases, read related literature, and raise their own questions. The instructors also prepared targeted problems based on the selected cases and required competencies, including case characteristics, diagnosis and differential diagnosis, examination and treatment. In the class, the students were asked to discuss questions related to the selected cases in small groups first; then, one representative student from each 
group answered the questions, and the instructors guided the students in writing a summary. In this way, the students could fully grasp and integrate all emergency medicine content and increase their ability to solve problems independently.

\section{Data evaluation}

Evaluation criteria After the completion of the course, the two groups of students were assessed, including the students' grades and satisfaction with the teaching method. All students took the same tests: theoretical tests (100 points), operational skills (100 points) and teaching satisfaction questionnaire (10 points). The questionnaire included six aspects: critical clinical thinking, enthusiasm toward learning, ability to analyze and solve problems, solid grasp of the content, teamwork ability and acceptance of the teaching method.

Teaching quality statistics After the completion of the course, 90 students took the same test and operational assessment. The test and assessment were conducted by the same senior lecturers, and the final results were statistically analyzed.

\section{Statistical analysis}

SPSS 19.0 statistical software was used. Measurement data are presented as the mean \pm standard deviation. $t$ tests were performed for comparisons, and $\mathrm{P}<0.05$ was considered statistically significant.

\section{Results}

\section{Students' scores of quizzes}

At the end of the course, two groups of medical students took the test and assessment. For the theoretical test, the average score in the experimental group [(90.89 \pm 4.249$)$ points] was significantly higher than that in the control group [(84.67 \pm 4.871$)$ points], and the difference was statistically significant $(P=0.01)$. In the operational skills assessment, the average score in the experimental group [(88.2 \pm 4.154$)$ points] was also significantly higher than that in the control group $[(80.62 \pm 4.942)$ points], and the difference was statistically significant $(P<0.01)$.

\section{Satisfaction survey}

Comparison of other aspects of the teaching methods There was no significant difference in knowledge gained between the two groups of students. For the medical students in the experimental group, critical clinical thinking ability, enthusiasm toward learning, the ability to analyze and solve problems, solid grasp of the content, and acceptance of the teaching model were significantly higher than those of medical 
students in the control group, and the differences were statistically significant $(P<0.05)$, as shown in Table 2.

\section{Discussion}

Emergency medicine is a special interdisciplinary field and covers a large number of medical specialties. In clinical practice, emergency patients present with acute and complicated diseases, including some occult diseases, which require clinicians to have comprehensive clinical knowledge and to have the ability to use that knowledge to screen and diagnose various diseases. Therefore, the training of students in emergency clinical medicine is more demanding [7]. In view of the challenges of teaching emergency medicine, we used the POGIL-based flipped classroom model to teach emergency medicine, in order to train students in active divergent thinking when learning emergency medicine.

The flipped classroom model is a new type of teaching model in which learning of general knowledge is performed by students before the class, but in-depth teaching, case studies and problem solving are conducted in the class with instructors [8]. The flipped classroom model restructures students' learning process, and information/knowledge transmission is carried out before class. The teacher not only provides videos but also provides online tutoring. Understanding the content is accomplished through interactions in class; additionally, teachers can know students' learning difficulties in advance and provide effective guidance in class. Communication among classmates is encouraged to promote learning by the students. Studies have found that in many other clinical medicine courses, the flipped classroom model can effectively stimulate students' interest in learning and improve students' critical thinking, practical abilities and ability to collaboration [9].

POGIL is a new student-centered teaching method. This teaching model uses situational teaching as the starting point and inquiry learning as main learning strategy. To gain knowledge regarding basic concepts, students are encouraged to study in groups and work in teams, aiming to increase students' innovative thinking ability and the ability to apply knowledge in new fields. The goal is to enable students to participate in the learning process and develop important clinical skills through learning and understanding basic concepts. Studies have shown that the "cramming" method is not suitable for most students and that students in interactive learning teams are more likely to succeed. Learning knowledge is a personal process, and when a student has the opportunity to build his/her own knowledge system, she/he can enjoy the learning process [10-11]. However, the POGIL model also has some shortcomings, such as incomprehensiveness, polarization of student performance, limited time for class and discussion, and student non-familiarity with the inquiry learning model.

To avoid disadvantages and further optimize the POGIL method, we used the POGIL-based flipped classroom model for teaching emergency medicine to improve teaching effectiveness. This study found that the POGIL-based flipped classroom model improved students' achievements in learning emergency medicine, improved students' interest in learning emergency medicine, and enhanced students' team collaboration and clinical thinking skills; therefore, this new teaching model was found acceptable by 
most students. There were no significant differences in the content taught between two groups. In the teaching model combining both POGIL and a flipped classroom, heuristic teaching was carried out for students based on case studies of various clinical diseases in emergency medicine, in order to fully mobilize students' subjective initiative and learning enthusiasm, increase students' team communication and collaboration skills, and improve students' first aid awareness and clinical skills.

\section{Limitations}

There are two limitations to this study. One is that the study is a single center study, so its results may not be generalizable to students in other colleges. Another limitation is that we assessed only the short-term results of the combined method. Therefore, further studies are required to investigate whether the benefits of this combined method extend to the long term as well.

\section{Conclusions}

In short, the POGIL-based flipped classroom model was applied to emergency medicine teaching and significantly improved student achievement and increased students' enthusiasm toward learning, indicating that it is an effective teaching model. However, this teaching model is still being developed and requires investigations and improvements by teachers and scientific researchers to ensure effective training of medical students.

\section{Declarations}

\section{Acknowledgements}

We thank all those who helped us in this study, in particular, the Department of Emergency for making this study possible.

\section{Potential Conflicts of interest}

All other authors: no conflicts.

\section{Funding}

This work was supported by grants from the National Natural Science Foundation of China (81600461日日 the Natural Science Foundation of Hunan Province (2019JJ40467ه区the Scientific Research Project of

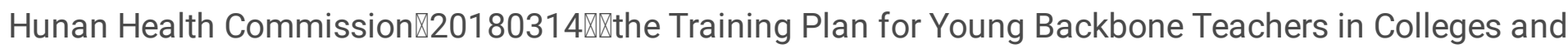
Universities of Hunan Province囚and the Research Project of Teaching Reform in General Colleges and Universities in Hunan Province.

\section{Ethics}


The study was approved by the Institutional Review Board and Ethics Committee of the Third Xiangya Hospital, Central South University. Written informed consent was obtained from all the participating students.

\section{References}

[1] Farrell S E, Hopson L R, Wolff M, et al. What's the Evidence: A Review of the One-Minute Preceptor Model of Clinical Teaching and Implications for Teaching in the Emergency Department[J]. Journal of Emergency Medicine, 2016, 51(3): 278-283.

[2]Brazil V. Past and future of emergency medicine education and training. Emerg Med Australas. 2014;26(1):69-71.

[3]Bassir SH, Sadr-Eshkevari P, Amirikhorheh S, Karimbux NY. Problem-based learning in dental education: a systematic review of the literature. J Dent Educ. 2014;78(1):98-109.

[4] Hart D, Bond W F, Siegelman J N, et al. Simulation for Assessment of Milestones in Emergency Medicine Residents [J]. Academic Emergency Medicine, 2018, 25(2): 205-220

[5]Bodagh N, Bloomfield J, Birch P, Ricketts W. Problem-based learning: a review. Br J Hosp Med (Lond). 2017;78(11):C167-C170.

[6]Roller MC, Zori S. The impact of instituting Process-Oriented Guided-Inquiry Learning (POGIL) in a fundamental nursing course. Nurse Educ Today. 2017;50:72-76.

[7]Sherbino J, Van Melle E, Bandiera G, et al. Education scholarship in emergency medicine part 1: innovating and improving teaching and learning. CJEM. 2014;16 Suppl 1:S1-S5.

[8]Beom JH, Kim JH, Chung HS, Kim SM, Ko DR, Cho J. Flipped-classroom training in advanced cardiopulmonary life support. PLoS One. 2018;13(9):e0203114.

[9] Njie-Carr VP, Ludeman E, Lee MC, Dordunoo D, Trocky NM, Jenkins LS. An Integrative Review of Flipped Classroom Teaching Models in Nursing Education. J Prof Nurs. 2017;33(2):133-144.

[10]Walker L, Warfa AM. Process oriented guided inquiry learning (POGIL $®)$ marginally effects student achievement measures but substantially increases the odds of passing a course. PLoS One. 2017;12(10):e0186203.

[11]Jaffe L, Gibson R, D’Amico M. Process-oriented guided-inquiry learning: a natural fit for occupational therapy education[J]. Occup Ther Health Care,2015,29(2):115-125.

\section{Tables}

Table 1 Comparison of general information between the two groups 


\begin{tabular}{|c|c|c|c|c|}
\hline \multirow[t]{2}{*}{ Group } & \multirow[t]{2}{*}{$\mathrm{n}$} & \multirow[t]{2}{*}{ Age (mean \pm standard deviation) } & \multicolumn{2}{|c|}{ Gender (n, \%) } \\
\hline & & & Male & Female \\
\hline Experimental group & 45 & $22.00 \pm 0.564$ & $19 \square 42.2 \square$ & $26 \square 57.8 \square$ \\
\hline Control group & 45 & $22.02 \pm 0.723$ & $17 \square 37.8 \square$ & $28 \square 62.2 \square$ \\
\hline
\end{tabular}

Table 2 Comparison of students' perspectives and self perceived competence between the two groups

\begin{tabular}{lccc}
\hline & Experimental group $(\mathrm{n}=45)$ & Control group $(\mathrm{n}=45)$ & $\mathrm{P}$ \\
\hline Critical clinical thinking & $9.031 \pm 0.3866$ & $8.478 \pm 0.4557$ & 0.004 \\
Enthusiasm toward learning & $9.098 \pm 0.2816$ & $8.564 \pm 0.4162$ & 0.002 \\
Ability to analyze and solve problems & $8.880 \pm 0.3079$ & $8.011 \pm 0.4682$ & $\square 0.001$ \\
Solid grasp of the content & $9.040 \pm 0.2597$ & $7.978 \pm 0.4567$ & $\square 0.001$ \\
Teamwork ability & $8.480 \pm 0.4192$ & $8.680 \pm 0.3609$ & 0.564 \\
Acceptance of the teaching method & $8.496 \pm 0.4095$ & $7.724 \pm 0.5275$ & 0.001 \\
Knowledge gained & $8.867 \pm 0.4758$ & $8.769 \pm 0.5138$ & 0.738 \\
\hline
\end{tabular}

\section{Figures}



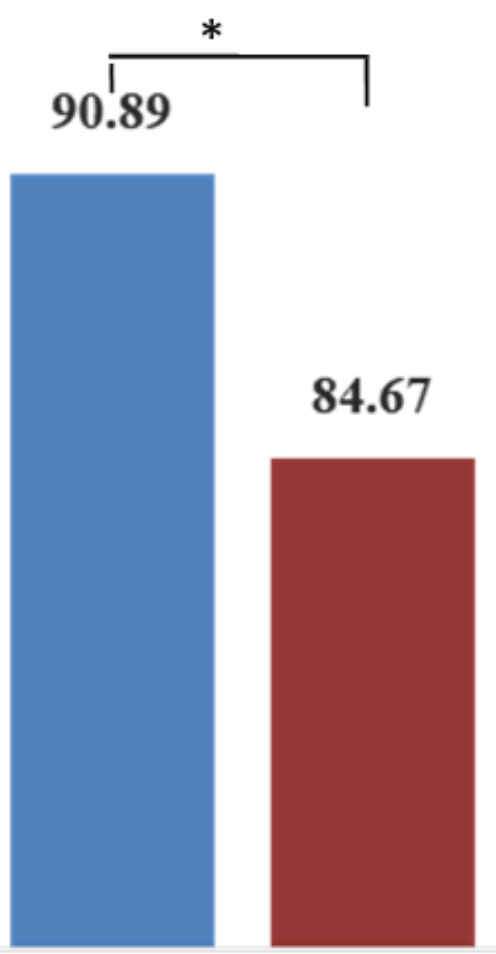

theoretical knowledge score

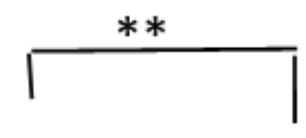

88.2

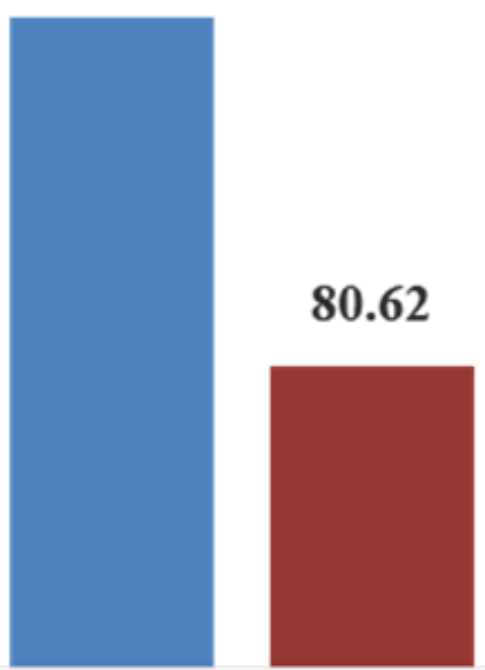

operational skills score

\section{axperimental group $\square$ control group}

\section{Figure 1}

Comparison of score on basic theoretical knowledge and operational skills between experimental group and control group, respectively. Data are presented as the means \pm standard deviation (SD); $p<0.05$, ** $p<0.01$ and NS: no significant difference. 